\title{
Geometrization Versus Transcendent Matter: A Systematic Historiography of Theories of Matter Following Weyl Norman Sieroka
}

\begin{abstract}
This article investigates an intertwined systematic and historical view on theories of matter. It follows an approach brought forward by Hermann Weyl around 1925, applies it to recent theories of matter in physics (including geometrodynamics and quantum gravity), and embeds it into a more general philosophical framework. First, I shall discuss the physical and philosophical problems of a unified field theory on the basis of Weyl's own abandonment of his 1918 'pure field theory' in favour of an 'agent theory' of matter. The difference between agent and field theories of matter is then used to establish a sort of dialectic meta-view. With reference to Weyl this view can be understood as being a particular Fichtean transcendental idealist approach which attempts to combine the strengths of the Husserlian phenomenology and Cassirer's neo-Kantianism.
\end{abstract}

\section{Introduction}

2 Weyl on Pure Field Physics and Agent Theories of Matter

2.1 Weyl's abandonment of pure field physics

2.2 The philosophical tradition of agent theories

3 A Weylian Classification of Recent Theories of Matter

3.1 Direct interparticle action

3.2 Wheeler's geometrodynamics

3.3 Geometrodynamics of gauge fields

3.4 Quantum gravity: quantum general relativity versus string theory

4 Wavering Between Freedom and Constraint 


\section{Introduction}

This article attempts to reconstruct Hermann Weyl's change between different ways of describing matter in physics and to investigate the philosophical significance of Weyl's systematic historiography of theories of matter which partly resulted from this change and according to which the history of physics exhibits - apart from early modern substantialist views on matter - a seesaw between field and agent theories of matter. (To keep a clear systematic and historical focus, my main sources for discussion will be Weyl's 1924 paper on 'Was ist Materie?' and the 1926/27 original edition of his Philosophie der Mathematik und Naturwissenschaft; i. e. not the revised English edition from 1949. ${ }^{1}$ )

A possible ongoing significance of Weyl's systematic historiography will be examined by applying it to some more recent theoretical approaches to matter in physics, namely to the Wheeler-Feynman action at a distance theory, Wheeler's geometrodynamics, the geometrodynamics of gauge fields, and quantum gravity (quantum general relativity and string theory); see Section 3. Finally, the wider philosophical significance of Weyl's systematic view on matter will be discussed in Section 4. Here, it will be shown to what extent this view is only a part of Weyl's general and rather particular transcendental idealist framework which follows from a specific reading of Fichte and which was brought forward by Weyl to strike a balance between the transcendentalist frameworks of Husserlian phenomenology and Cassirer's philosophy of symbolic forms (cf. Friedman, [2005], p. 28).

To begin with, and to enable a better understanding of his philosophical intentions around 1925, something must be said on Weyl's abandonment of his 1918 unified field theory. So Section 2 gives a brief discussion of both the mathematical-physical as well as the philosophical reasons for Weyl's turning away from what he calls 'pure field theory' (reine Feldphysik) and towards an 'agent theory' (Agenstheorie) which takes matter to be transcendent; i.e., to be beyond space and time. Whether also the stronger claim according to which matter is a transcendental precondition for the constitution of spatio-temporal events holds true for Weyl's agent theory, is something to be discussed then as well. Admittedly, this kind of philosophical move might appear rather alien to an analytic audience which usually does not stand so much under the influence of transcendental philosophy and post-Kantian Naturphilosophie as Weyl did. However, given that several Husserlian and Fichtean inheritances in Weyl

1 Those texts are obviously Weyl's most ambitious ones concerning a systematic approach towards theories of matter; and they both fall within the same period of Weyl's own physical understanding of matter. For Weyl's changing concept of matter between 1918 and 1930 see also (Scholz [2007]). 
have been established over the last few years, ${ }^{2}$ the following investigation of the relevance and pertinency of Weyl's changing view on matter, in relation to his peculiar philosophical and historical reflection on it, suggests itself.

\section{Weyl on Pure Field Physics and Agent Theories of Matter}

\subsection{Weyl's abandonment of pure field physics}

According to Weyl's section on matter in his 1926/27 Philosophy of Mathematics and Natural Science, early modern times started with assuming that matter is substance. Matter was assumed to be, one might say, self-contained and self-sufficient and it was assumed to be the bearer of properties such as mass and extension. However, as Weyl shows, the development of physics, in particular since the eighteenth century, made it plausible that so-called substantial properties could be understood in terms of dynamics and without assuming a separate bearer. In particular, this development was fostered by the growth and consolidation of electromagnetism; and with this field theoretic views of matter more or less replaced substantialist views. Indeed, it even became tempting to reduce matter completely to (classical) fields. A very influential example of such a 'pure field theory', as Weyl calls it, is the electromagnetic programme by the German physicist Gustav Mie. Roughly speaking, Mie wanted to reduce all forces to electromagnetic fields and claimed that matter was nothing but knots in the all-embracing electromagnetic field as being the 'world substance' or 'world ether' (Mie [1912a], [1912b], [1925]; cf. also Vizgin [1994], pp. 26-38; and Weyl's statements about Mie in Weyl [1921]).

This was in 1912 and three years later the next important pure field theory was suggested by Hilbert (Hilbert [1915]); and another three years later it was Weyl himself who brought forward such a theory (Weyl [1918], [1919]). Since it was now 1918, Weyl could start from a different classical field theory, namely, general relativity. Also, intuitively this might be a more promising approach as compared with Mie, since one now tries to dissolve matter into time and space instead of into electromagnetism. ${ }^{3}$ Arguably, and as Weyl himself acknowledges, the programmatic idea of his unified field theory is similar to Mie's. In both cases the philosophical background assumption is that of matter being reducible to fields and - since Weyl understood pure field

2 As for the influence of Husserl on Weyl's 1918 unified field theory and that of Fichte on Weyl's later agent theory see (Ryckman [2005]; Sieroka [2007]), respectively. Cf. also (Sigurdsson [1991]).

3 For more on this approach see, for instance (Sigurdsson [1991]; Scholz [1995]; Ryckman [2005]). Let me also add that one of the main problems of Mie's approach was the fact that it had to attribute physical relevance to the absolute value of the electromagnetic potential; cf. (Pauli [1920]). 
physics as an attempt towards a 'world geometry' (cf. Ryckman [2005])—as being reducible to geometry. Accordingly, in his philosophical reflection of 1926/27, Weyl showed a direct historical line from the old Cartesian assumption of matter being pure extension (res extensa) to modern pure field theoretic approaches. For Descartes had already claimed that 'all natural phenomena can be explained [by using the principles of geometry] and any other principles in science are neither allowed nor desirable' (Descartes [1992], p. 63, Part 2, para. 64).

Independently of his own historical reconstruction of such a tempting reduction of matter, Weyl himself became sceptical about his own 1918 unified field theory and indeed about all attempts in pure field physics by about 1920 . The major physical reason for this was the problem of discreteness or, as Weyl puts it, of the 'grainy' (körnig) structure of reality. All field theories are fundamentally continuous and all approaches towards a unified field theory (be it Mie's, Hilbert's, Einstein's or Weyl's) suffered from the fact that they could not deduce things like the existence of an elementary charge. And that it was indeed this general worry that convinced Weyl to abandon pure field physics (and not so much the detailed criticisms against certain aspects of his particular 1918 approach), this can be seen from several sources: obviously Weyl was not much impressed by Einstein's famous criticism and replied by distinguishing between what he called 'adjustment' (Einstellung) und 'persistence' (Beharrung) ${ }^{4}$ And also the several detailed criticisms in Pauli's famous encyclopedia entry on relativity are not particularly discussed or acknowledged by Weyl as being fatal for his theory. ${ }^{5}$ However, what stuck was the following very general criticism by Pauli:

Whatever one thinks about these arguments in detail, one thing is for sure, namely that new elements which are alien to the continuity concept of fields must be added to the basis of these theories [the unified field

4 The question whether this is a physically satisfying response or whether it detaches his theory from experience is not something I will discuss here as this has been dealt with in detail elsewhere; see (Fogel [2008]). The only philosophically relevant point to mention here is that Weyl called the process of adjustment of, e.g., the charge of an electron one of 'ideal positing' (ideale Setzung); cf. (Weyl [1928], p. 149). Given Weyl's close acquaintance with Fichtean philosophy the term 'positing' seems to be no coincidence but rather hints at his assumption of some transcendental constituting processes (see below; the term 'ideal' seems to point to Hilbert's method of ideal elements, which arguably must be posited as well).

5 These criticisms mainly are: the fourth-order nonlinear differential equations of Weyl's approach are much too complicated for a theory which should be physically motivated; within Weyl's approach gravitational attraction and electric repulsion should balance one another, but because of $e / \sqrt{G m} \approx 10^{20}$ this seems hopeless; the differential equations for positive and negative electric charges are the same (this was considered a problem around 1920 since in those days the hydrogen nucleon - with a mass of around eighteen hundred times of that of an electron! - was considered to be the positive 'counter-particle' of the electron); cf. (Pauli [1920], pp. 759-75). 
theories of Mie, Einstein and Weyl] to arrive at a satisfactory solution to the problem of matter. ${ }^{6}$

Also for Weyl it had not been some inner-theoretic details that made him abandon his unified field theory, but rather this general concern about the relation between continuous fields and discrete matter; and indeed in Weyl's case this concern was intimately connected to his views on the mathematical continuum and on some of his philosophical convictions. (More recently, there has also been the assumption that Weyl abandoned his 1918 approach mainly or only because quantum mechanics provides an absolute unit of length which his field theory lacked. But this is not even physically convincing, since Weyl could also admit such an absolute standard of length within his approach by means of 'adjustment' (Fogel [2008], pp. 47-51). Moreover, the strongest evidence one finds in favour of this view dates from around 1930 when the new gauge principle was also already in place (Weyl [1929], [1931b]). So arguably these are historically delicate sources for understanding Weyl's abandonment of pure field theory in the first place, i.e. around 1920.)

Weyl explicitly criticized field theories because of their conceptual opposition to findings about the atomic realm. The latter, according to Weyl, 'is widely dominated by integral numbers' whereas field physics can only describe a 'silent continuous flow' and 'completely rests in continuity' (Weyl [1927], pp. 130 and 133). But how does this lead to an agent theory with its peculiar explanation of the ongoings in the atomic realm? To understand this, the scope in which Weyl's considerations took place must be widened towards Weyl's mathematical attempts to tame the tension between continuity and discreteness (which was already a major topic in his 1918 Das Kontinuum), and towards his philosophical approach on causation and time (which was indicated in the last quote by Weyl's usage of the terms 'silent' and 'rests').

That indeed Weyl's move towards an agent theory has something to do with inner-mathematical considerations is already evident from the first source for his abandonment of pure field physics. In a letter to Pauli in December 1919, when Weyl already knew the aforementioned criticisms, he wrote that he is 'deeply convinced that statistics is something which is independent in principle from "law"; for it is altogether self-contradictory, to imagine a continuum as being something finished'. 'By 'law' Weyl here means the functional relations within field physics as opposed to the relations describing the atomic realm which he assumes to be fundamentally probabilistic (cf. Weyl [1920]).

6 'Wie immer man sich im Einzelnen zu diesen Argumenten stellen mag, so viel scheint sicher zu sein, daß zu den Grundlagen der bisher aufgestellten Theorien erst neue, der Kontinuumsauffassung des Feldes fremde Elemente hinzukommen müssen, damit man zu einer befriedigenden Lösung des Problems der Materie gelangt' (Pauli [1920], p. 775).

7 ETH-Bibliothek, Archive, Hs 176: 1 ('Denn ich bin fest überzeugt davon, daß die Statistik etwas prinzipiell Selbständiges gegenüber [...] dem "Gesetz" ist; weil es überhaupt widersinnig ist, sich ein Kontinuum als etwas fertig-Seiendes vorzustellen.') 
(Sometimes Weyl even speaks of field physics as being 'pure law physics'; reine Gesetzesphysik.) So Weyl thinks that in the case of the latter, statistics plays a genuine role; and so this case is unlike those where one uses statistics just as an abbreviating tool in order to enable a description of systems which would otherwise be too complex to handle.

Taking those points together, what Weyl is seeking is a kind of 'process account' of a continuum which is not governed by some law or algorithm but which could only be described by means of statistics; and one obvious candidate for him around 1920 would be L. E. J. Brouwer's free choice sequences. (Since so much has been written on Weyl's short-term alliance with intuitionism, it might be enough for present purposes to remind the reader that according to Brouwer's approach a continuum is understood to be a 'medium of free becoming' because it is generated by a process of ongoing free decision making. The mathematician has to come up again and again with natural numbers to construct a continuum; and so a mathematical description of this spontaneous process itself could only be given by means of statistics. ${ }^{8}$ )

A different, and perhaps less well-known candidate, would be the collectives (Kollektivs) of Richard von Mises. von Mises's 1919 Grundlagen der Wahrscheinlichkeitsrechnung was (until the work by Kolmogoroff in 1933) the standard work in the foundation of statistics. It gives an account of probability in frequentist terms and starts from a notion of collectives as stable and lawless sequences of observations (von Mises [1919], pp. 55-8). Indeed just like in Weyl's case, von Mises's motivation here was the conviction that statistics (as opposed to pure law) plays a genuine role in descriptions of physical reality (See Ibid., and more explicitly von Mises [1928], p. 178). Though admittedly von Mises's conviction originated from his understanding of Brownian motion and thermodynamics rather than from quantum mechanics, the parallels to Weyl in seeing this close connection between the foundation of physics and statistics (and indeed also geometry) are striking; and in a way they hint at a possibility of naturalizing Brouwer's choice sequences. ${ }^{9}$

With this (indeed rather vague) idea of a naturalized process of decision making, Weyl could now interpret the ongoings in the atomic realm as being similar to what the spontaneous mathematician is doing with his

8 To avoid rather subtle discussions which would blur the focus of this article, I will use the terms 'spontaneous' and 'free' synonymously here and leave a more detailed discussion of what might be a relevant natural philosophical difference between them for another occasion.

9 The reason for Weyl's and von Mises's assumption of this close connection might have very well been the formulation of the sixth problem in Hilbert's famous list of mathematical problems from 1900 which also combined geometry, statistics, and the foundation of physics; see (Hilbert [1900]) and recently (Hochkirchen [1999]). Since it is fairly certain that Weyl knew von Mises's work, one might speculate why Weyl does not refer to it directly. Perhaps this was due to von Mises's pure frequentism (as opposed to a chance or propensity interpretation of probability) and his complete denial of causality; cf. (von Mises [1928], pp. 170-9). For arguably both assumptions fit into field rather than into agent theories of matter. 
choice sequences. Like the mathematician who is generating or constituting a continuum, atomic events spontaneously generate the space-time continuum. Weyl hence also speaks of the 'realm of quantum decisions' (cf. Weyl [1920], p. 122). So space-time itself is thought to be evolving in an infinite process both inwards and outwards. As time proceeds, Weyl argues, there is not only an 'outward development' (i.e. time does not only 'go on') but it also becomes 'more fine-grained'. ${ }^{10}$ Since the details of this process have already been elaborated on elsewhere (Sieroka [2007]), and since the details of Weyl's account also slightly changed over time, it seems sufficient here to emphasize that Weyl (at least up to mid-1920s) generally adhered to the view that there must be an intimate connection between statistics and the construction or description of a continuum. ${ }^{11}$

\subsection{The philosophical tradition of agent theories}

So in a sense matter and man draw near in Weyl's agent theory. Both are viewed as somehow being capable of decision making, as being active and spontaneous. Indeed, this rapprochement of matter and man is in line with what throughout his 1926/27 book Weyl says about man as being both a natural and a conscious being and about the mind-body relation. Here, Weyl's argumentation is within a typical 'continental' tradition and starts from a concept of the ego as being fundamentally active; a concept one most prominently finds in Fichte. Together with this, Weyl claims that it is only because human beings experience themselves as 'I am doing something', as being causes in the world and also as feeling resistance from outside bodies, that the notion of cause and effect arises (Weyl [1927], pp. 147-9). ${ }^{12}$ (This view is, of course, strikingly different from Hume's account of causation as a constant conjunction. Consequently, Weyl describes the Humean account as the ancestral view for what is left of causation in field physics, namely functional relations (Weyl [1927], pp. 144-5). ${ }^{13}$ ) For Weyl causation in the philosophical (not the modern physical) sense has something to do with agency and so pure

10 As Weyl makes explicit (ibid., pp. 121-2) this inward becoming is indeed more than the relativistic effect that with the temporal proceeding of the light cone more and more past events come into view.

11 See in particular (Weyl [1988], p. 12), where he speaks no longer of Brouwer's free choice sequences, but still in the context of discussing continuous manifolds claims that 'the contemporary state of physics indicates [...] a probabilistic approach'.

12 See also (Weyl [1932], p. 31), where 'acting upon from beyond' (Hineinwirken) is described as the primal experience of causation.

13 See also (Hume [1975], p. 67, footnote), for a rather weak reply against an experiential ('I am doing this') view of causation. Notably, however, Weyl's experiential view of causation of around 1925 also deviates considerably from his own phenomenological framework of 1918; cf. (Tietjen [1980]; Sieroka [2007]) for some general differences in a Husserlian as compared with a Fichtean view on subjectivity, space-time, and causation.) 
field physics in which one aims at reducing matter to fields is in this philosophical sense not a causal theory. There are no agents, hence no causes and effects, and hence field physics is 'silent', as he put it above.

In contrast, the agent theory is meant to put matter back into its 'right of causal efficacy' (Wirklichkeitsrecht). Weyl here refers to Leibniz as the 'ancestor of all modern dynamical views of matter'; i.e., of all agent theories (indeed Weyl's usage of the Latin term 'agens' is borrowed from Leibniz). In sharp contrast to Descartes as being the founding father of pure field theory, for Leibniz 'there is something to material objects apart from extension, even prior to extension' that 'constitutes the innermost nature of matter' (Leibniz [1982b], p. 3). For Leibniz matter is not the object of pure geometrical treatment but is foremost acting and hence is a metaphysical substance like a 'soul' (Ibid.). Similarly, also in Weyl's agent theory the concepts of matter and consciousness (or soul, or ego) are tied together by emphasizing their spontaneous activity (Weyl [1924], pp. 493 and 510, [1923], pp. 5-6).

What is more, and here again Weyl follows a whole tradition from Leibniz to Fichte, Schelling and others, it is causation that gives the directedness of time. According to this view, the earlier-later relation is a consequence of the relation between causes and effects. Correspondingly, pure field physics insofar as it fails to incorporate matter as a causal agent also fails to account for the experienced directedness of time. For Weyl, this is also plausible given the physical formalism of field physics which is invariant under time reversal. In contrast to this, statistics (being the key concept in quantum mechanics) brings temporal directedness into physics because in statistics we always 'deduce the probable state at a subsequent moment [...], and not the state at a previous one' (Weyl [1932], p. 49; cf. also Weyl [1921], pp. 240-2 and 255-6). (Admittedly, this is a rather weak argument. But instead of criticizing it in detail, let me say a little more on the relation between matter as an agent and the constitution of space now. For together with what has been said about agency, causality and time this will top off the discussion of Weyl's agent theory and will enable me to show its origin in the aforementioned philosophical tradition.)

In his 1921 paper on field and matter, Weyl showed that it is a consequence of general relativity and electrodynamics that it makes no sense to describe the inside of a particle, for within it-like within a black hole - classical field physics breaks down. ${ }^{14}$ Further, by using Gauss's theorem (i.e., by turning all relevant volume integrals into surface integrals) Weyl shows that everything which was so far described as being a property of a particle can equally well be described by looking exclusively at some spatio-temporal

${ }^{14}$ Ibid. It is also in this paper (p. 242) that Weyl claims that 'for cogent reasons field theories of matter made me mad' ('bin ich jedoch, aus triftigen Gründen an der Feldtheorie der Materie irre geworden'). 
neighbourhood (Umgebung) where fields can be measured. This result is relevant for physics because the description of extended bodies was known to be a serious problem for field theories for quite some time. ${ }^{15}$

These considerations originated in the context of a classical-relativist approach to matter in terms of singularities, which was defended by Weyl only for a very brief period and according to which space-time is no longer a simply connected manifold, but rather like a Swiss cheese. ${ }^{16}$ However, in a sense these considerations retained their philosophical importance for Weyl also after the dawn of quantum physics. Weyl still emphasized the notion of a spatio-temporal neighbourhood around the middle of the 1920s. He then said that one should not dispense with matter altogether, but one should dispense with the assumption that it is spatially extended (Weyl [1923], p. 288, [1924], p. 510). ${ }^{17}$ All space consists of, according to Weyl, are neighbourhoods in which one might measure field effects. But there is no spatio-temporal inside or boundary of particles. To put it bluntly: matter gets 'thrown out of space-time'. It is assumed by Weyl to be non-extensive or 'extramundane'. Matter is an agent in the sense that it stands 'behind' the fields, that it excites and determines them 'from beyond' (Ibid.). The four-dimensional fields themselves then are only the 'forceless transmitters' of an extramundane activity. ${ }^{18}$

Around 1926, Weyl speculates further about how this extramundane realm from which matter constitutes spatio-temporal events could be described. He suggests that the infinite-dimensional Hilbert space of quantum mechanics might be the 'extramundane location' of matter and that the quantum mechanical projection operators might account for the causal efficacy that matter has in spatio-temporal reality (Weyl [1927], pp. 142-3). Here, Weyl's argumentation also coincides with what has already been said about statistics and about decision making; namely that four-dimensional space-time can be described by the non-causal (meant in Weyl's philosophical sense) functional relations of field physics, whereas the extramundane realm of matter can only

15 It was proved by Poincaré ([1906]) that if one assumes an electron to be a pointlike particle, then its static energy turns out to be infinite; and that if on the other hand one assumes an electron to be an extended object, then an additional interaction would be needed to prevent the electron from bursting due to its inner electrostatic repulsion.

${ }^{16}$ See (Scholz [2007]) for details. Weyl states that from a mathematical point of view there is no problem with such a rather complex topological structure of space-time; see (Weyl [1921], p. 253). For a more recent discussion of what general relativity would look like in multiconnected spaces, cf. (Lachieze-Rey and Luminet [1995]).

17 ('Danach ist das Materieteilchen selber nicht einmal ein Punkt im Feldraume, sondern überhaupt nichts Räumliches (Extensives), aber es steckt in einer räumlichen Umgebung drin, von welcher seine Feldwirkungen ihren Ausgang nehmen.')

18 See also Weyl's letter to Felix Klein from 1920, quoted in (Sigurdsson [1991], p. 204) (though my translation slightly differs): 'Finally I liberated myself from Mie's theory of matter thoroughly and I have achieved a new position with respect to the problem of matter. Field physics no longer appears to me as the key to reality. Just the opposite: the field, the ether, now appears to me only as a transfer medium of effects, which in itself is only a completely forceless transmitter. Matter, however, is the reality beyond the field and determines its states.' 
be described by means of a probabilistic theory. For, it is the realm of causal agents and decision making.

Whereas it should be undisputed that according to Weyl's agent theory matter (together with the ego) exists beyond space and time, it might be questionable how seriously one should take the idea that time only follows from causes and effects originating from the spontaneous activity of this agent, and that the spatial appearances one can measure in terms of fields are always (and only) the effects of extramundane matter. So the question which arises is whether matter as an agent is not only transcendent but also transcendental; i.e., whether it is not only 'extramundane' but also the precondition for the possibility of space and time. For without the spontaneous activity of matter (and ego) there would be no directed time and there would be no fields.

Within so-called 'continental philosophy', there is a rather strong tradition of viewing matter as being the transcendental precondition for space and time. And, as Weyl acknowledges in the preface of the revised English edition of Philosophie der Mathematik und Naturwissenschaft, the original edition was strongly influenced by this transcendental idealist tradition in philosophy (Weyl [2000], p. 5). Indeed, it is only the original version in which Weyl devotes a separate section to agent theories of matter. In this section, Weyl explicitly refers to Schelling as the one who had 'an idea which anticipated the modern development' of the agent concept of matter (Weyl [1927], p. 134).

According to Schelling's 'natural philosophy' (Naturphilosophie) 'what fills space cannot be matter' (Schelling [1985], p. 360). ${ }^{19}$ For him matter is 'pure intensity' and is located beyond space and time (Ibid., pp. 360-1). Furthermore, the three-dimensionality of space is, according to Schelling, a direct consequence of the three physical forces inherent to this extramundane matter. ${ }^{20}$ Surely the details of Schelling's approach seem rather absurd from a contemporary perspective. Also Weyl does not adopt those details. His interest lies only in the general idea of matter being a transcendental precondition for spatio-temporal events, and he plays around with this idea.

Already a few years earlier when claiming that fields are only forceless transmitters of extramundane activity, Weyl wrote that the 'cause' or 'foundation' of physical reality 'is not grasped' by field physics; for him field physics 'does not say anything about the core-content of reality', but rather covers only the 'surface aspects of a necessity that is "not of this world". ${ }^{21}$

19 'Was also den Raum erfüllt, kann nicht Materie sein'.

${ }^{20}$ Cf., e.g., (ibid., p. 389), where he speaks of magnetism, electricity, and chemical processes as being the 'general schemes of the construction of nature', each being responsible for the construction of one spatial dimension. See also (Schelling [2000], pp. 37 and 108-19).

${ }^{21}$ Quoted from an open letter of Weyl, published in (Bovet [1922], p. 903) ('[ . . .] aber über das inhaltlich-Wesenhafte der Wirklichkeit machen sie [die physikalischen Gesetze der Feldtheorie] nichts aus, der Grund der Wirklichkeit wird in ihnen nicht erfasst. Zwar lassen sie nicht jeder 
Subsequently, Weyl also offers a philosophical speculation about what the essence or 'inner constitution' of matter as an agent might be; namely 'life and will' (Weyl [1924], p. 510). ${ }^{22}$ Indeed, Fichte used the terms 'life' and 'will' synonymously in two versions of his Wissenschaftslehre and they exactly refer to the workings of the productive imagination in constituting the external world (cf. Schäfer [1967], pp. 174 and 195-222). Also what Weyl said above about the role of quantum decisions is nearly what both Fichte and Schelling say about the 'real' and the 'ideal activity' of the productive imagination. ${ }^{23}$ Given Weyl's expertise, especially on Fichte, it is unlikely that this is just a coincidence. Again, this is not meant to say that Weyl followed Fichte or Schelling in detail. Weyl even makes it explicit that what he says about preconditions or the inner development of space-time is more like some sort of guess work (Weyl [1920], p. 122). However, the fact that he does this guess work shows that he is acquainted with this particular philosophical tradition and that indeed he has at least some general sympathy towards it.

Also the way in which Weyl brings together matter and consciousness (without equating them) is similar to what Fichte says. Like Fichte, Weyl argues that there is a necessary connection between an ego and its body. The body is assumed to be the sphere of the ego's free actions; indeed, the body is thereby constituted by transcendental spontaneity and appears as a spatio-temporal neighbourhood (Fichte [1979], pp. 56-61; cf. Weyl [1924], p. 510, [1927], p. 133). (One could carry on this discussion and complement it with what Fritz Medicus - whom I will come back to later-said about Weyl's agent theory. ${ }^{24}$ However, for present purposes the hints at Weyl's specific transcendental idealist background might be sufficient and so I would rather briefly sum up the conclusions of this section.)

If one takes together both Weyl's scientific and his philosophical considerations and convictions, one might summarize the respective costs and benefits of a pure field theory and an agent theory as follows: all one could ideally get from a pure field theory would be a unification of electromagnetic and gravitational phenomena in physics; the chances of getting quantum mechanics into the picture (let alone the mathematical analysis of the continuum or

Laune und Willkür freie Bahn, aber nichts hindert uns, sie als einen Oberflächen-Aspekt einer Notwendigkeit aufzufassen, die "nicht von dieser Welt" ist.').

22 'Was dieses felderregende Agens aber seinem inneren Wesen nach auch sein mag - vielleicht Leben und Wille - [...]'. He uses the same terms (Leben und Wille) also in (Bovet [1922], p. 904).

23 See, for instance, (Fichte [1997], pp. 211-29), and (Schelling [1985], pp. 355-7), though obviously there is a difference between the two as to whether the productive imagination might be something in nature (so to speak 'de-personalized') or not.

${ }^{24}$ See (Medicus [1926]), on the notions of blind necessity and productivity in nature, or on how the agent theory turns matter from an 'it' $(E S)$ into a 'you' $(D u)$ and thereby kind of naturalizes Fichte's transcendental argument from the Naturrecht about intersubjectivity being a precondition for subjective freedom. 
the philosophical concern about human beings as part of nature) would be very limited. In contrast, if the agent theory could be worked out further, it would not only be able to describe electromagnetic and gravitational phenomena, but would also include quantum mechanics, and together with it a satisfying understanding of space-time (as being an inward and outward developing entity), and also understanding of human beings as part of nature (having physical bodies, making decisions, experiencing their causal efficacy and a flow of time). Although this is not meant as an a priori argument against the programme of 'pure field physics', Weyl's project of an agent theory follows to a large extent the tradition of a Schellingian Naturphilosophie and a Fichtean transcendental philosophy of nature. One might also view it as an accomplishment of a Leibnizian agent theory with 'quantum monads' being the basic constituents of (transcendent) matter. Within such an interpretation, field physics - which describes only the transmission of forces through space and time - accounts for what according to Weyl was still missing in Leibniz, namely 'the communication of the monads' (Weyl [1924], p. 510). ${ }^{25}$

\section{A Weylian Classification of Recent Theories of Matter}

Having discussed the different mathematical, physical, and philosophical concepts and concerns involved in Weyl's distinction between field and agent theories of matter, and given that Weyl claims that this distinction has been in place since the early modern period, the obvious question to ask now is whether this distinction is applicable to theories of matter dating from after 1926. Admittedly, the physical approaches, or theories, to discuss now are philosophically much less ambitious than especially Weyl's agent theory was. However, as will be shown, the concerns about whether matter can be reduced to geometry, or about how the directedness of time is related to causation, have been pretty much in place in physics as well during the second half of the twentieth century.

I shall start my Weylian classification of some recent theories of matter with the direct interparticle action view of Wheeler-Feynman and Wheeler's geometrodynamics. Admittedly, these approaches are of no particular relevance for contemporary physics, but they will allow a few more words about what Weyl called substance theories of matter and which I have only mentioned in passing above. Further, they nicely illustrate how Weyl's philosophical considerations about a dualism of matter and field - and whether it should be overcome or not-showed up from time to time also in the second half of the twentieth century. Moreover, Wheeler explicitly claims that with his (classical)

${ }^{25}$ Remember that according to Leibniz each lump of matter is a metaphysical substance; i.e., has a monadic structure and does not interact with other substances; famously, 'monads do not have windows' (Leibniz [1982a], p. 29, para. 7). 
geometrodynamics he stands in the tradition of Weyl, as do contemporary self-proclaimed successors of Wheeler who argue for some geometrodynamics of gauge fields which I shall also discuss below. Finally, the two currently prominent attempts to quantize gravitation, namely the direct quantization of general relativity (in its different facets) and string theory, will be evaluated against Weyl's distinction between field and agent theories of matter.

\subsection{Direct interparticle action}

In 1949, John Wheeler and Richard Feynman developed a theory of matter that aimed at a classical mechanical description of a system of interacting point-like particles without having to assume self-interaction (Wheeler and Feynman [1949]). Since the problem of self-interaction only occured in the post-Newtonian age of field physics, Wheeler and Feynman claimed their theory to be the 'natural and self-consistent generalization of Newtonian mechanics to the four-dimensional space of Lorentz and Einstein' (Ibid., p. 426). And, as in Newtonian mechanics, they assume that particles do interact directly over distance and so name their approach 'direct interparticle action'.

Although this theory does not involve 'fields' as being independent degrees of freedom, it still turns out to be mathematically equivalent to what Wheeler and Feynman call an 'adjunctive field theory'. Within the adjunctive field theory, the motion of a particle $a$ is given by the sum of the 'fields' (forces) of all particles acting on $a$ but without any contribution by $a$ itself. More relevant for the following philosophical discussion, however, is the fact that the adjunctive fields are given (one half each) by the retarded and the advanced solutions of the Maxwell equations.

This approach is exactly what Weyl dubbed a substance theory of matter. With its assumption of direct particle interaction and also its explicit reference to Newton, it shows itself as being within a tradition where there are no (genuine) fields but where matter is the only inhabitant of space and is self-contained. Besides which, given that classical mechanics like electromagnetism is invariant under time reversal, the Wheeler-Feynman approach can account neither for Weyl's strong concepts of cause and effect, nor, as a consequence, for the directedness of time. But here it is striking to see how Wheeler and Feynman are trying to turn this into an advantage of their theory. For they claim that with the equal contribution of the retarded and the advanced solutions of the Maxwell equations, "the symmetry between past and future in the prescription for the fields is not a mere logical possibility, as in the usual theory, but a postulational requirement' (Ibid., p. 426). They even see a direct link between the directedness of time and causation and indeed bite the bullet by claiming that 'the distinction between cause and effect is 
pointless' (Ibid., p. 428). These claims must, of course, be read in opposition to field physics where by an ad hoc stipulation only the retarded solutions are considered. Therefore, Wheeler and Feynman think that they have accomplished what so far was only aimed at in physics. Weyl, however, would presumably rather view this denial of causation as a consequence (or even as the completion) of a Humean tradition and as a great step backwards in approaching matter. Not only is a miraculous action at a distance, which was overcome in field theory, reintroduced but also the major drawbacks of field theory (no genuine causation, no directedness of time) are still in place in the Wheeler-Feynman approach.

\subsection{Wheeler's geometrodynamics}

A prominent attempt to develop pure field physics within the second half of the twentieth century was John Wheeler's geometrodynamics. Like Weyl's unified field theory of 1918, Wheeler's project was particularly motivated by general relativity and also aimed at reducing matter to the geometrical features of space-time. ${ }^{26}$ However, it also shares a feature with Weyl's agent theory because it assumes that space-time is not a simply connected manifold. ${ }^{27}$ Let me explain all this in some more detail.

Wheeler claims that 'in geometrodynamics, mass and charge are not idealized as properties of point particles, they are, instead, aspects of the geometrical structure of space' (Misner and Wheeler [1957], p. 595-6). According to this view something that appears to us as being matter is just a circulating lump of electromagnetic and/or gravitational radiation that is kept together by its own gravitational force. Wheeler calls such lumps 'gravitationalelectromagnetic entities', or 'geons' for short. He says: 'To the outside the geon manifests mass, but inside there is nowhere that one can put his finger and say "Here is 'real' mass!"' (Wheeler [1961], p. 65). And what appears to be a positive and a negative charge are nothing but a bunch of electric field lines which are so to speak 'added to the normal space-time container' like a handle on a mug; and it is because of the normally poor resolving power of the observer that the two ends of such a handle behave or 'look' like a positive and a negative elementary electric charge (Ibid., p. 78). ${ }^{28}$ However, strictly speaking there is again, as Wheeler emphasizes, 'nowhere that one can put his

${ }^{26}$ Wheeler ([1961], p. 78) defines his project as being 'that formulation of standard general relativity in which attention is restricted to curved empty space, free of all singularities and of all "real masses", which lie outside the framework of classical physics'.

27 Indeed Misner and Wheeler ([1957], p. 532), explicitly claim to stand in the tradition of Weyl here. They refer to (Weyl [1927], p. 64), which might indeed be inappropriate given the counterfactual inflection of this passage; see also (Mancosu and Ryckman [2005]). For the general influence of Weyl's thinking on Wheeler cf. (Wheeler [1986]).

${ }^{28}$ Wheeler famously called these handles 'wormholes'. 
finger and say, "This is where some charge is located.", (Misner and Wheeler [1957], p. 532).

These handles then turn space-time into something topologically complex. But although such a complex topology also followed from Weyl's agent theory, the view here is strikingly different. In Weyl's case, the complex topology followed from the fact that matter is beyond space and time ('extramundane'); in Wheeler's case it follows from the fact that matter is to be dissolved 'innermundanely' in space-time. From a Weylian perspective, then, geometrodynamics is an example of a purely field theoretic approach that 'completely rests in continuity'; and so it does not come as much of a surprise that this approach, as I will explain now, has serious problems accounting for quantum phenomena.

The aforementioned concepts of mass and charge within geometrodynamics are those of general relativity and classical electrodynamics; i.e., up to now nothing has been said about quantum physical concepts. But Wheeler announced his programme around 1960, and his claim was that quantum physics should be incorporated in his approach. He writes that 'we would hardly have taken up the analysis of classical geometrodynamics if we did not hope to find out what, if anything, quantum geometrodynamics has to do with elementary particle physics' (Ibid., p. 534; see also Wheeler [1968]). However, the obvious difficulty is to account for all the quantum phenomena we know of today-including strong and weak processes as completely new types of interactions - exclusively in terms of properties of four-dimensional space-time. $^{29}$ (At least one further property that might come to mind here would be torsion. If space-time can have holes and handles, why after all should it not be twisted as well? Indeed, the basic mathematical idea here goes already back to Élie Cartan; and within geometrodynamics the concept of torsion amounts to an introduction of spin (cf. e.g. Hehl [1973]). However, this is hardly enough for the full-blown 'quantum geometrodynamics' Wheeler demands.)

So at least as far as quantum physics is concerned Wheeler's original geometrodynamics, with its attention being restricted to curved empty space, pretty much got stuck on the level of being a programmatic proclamation; and it seems that only a considerable widening of the notion of geometry could get it under way again.

${ }^{29}$ Other problems of Wheeler's approach include the huge mass, which indeed is not even constant, and diameter of a geon which would be $>10^{39} \mathrm{~g}$ and $>10^{11} \mathrm{~cm}$, respectively. So it is very difficult to relate geons to what we usually think of as being fundamental physical entities; as (Wheeler [1961], p. 66), acknowledges, geons 'have not the slightest direct connection with the world of elementary particle physics'. 


\subsection{Geometrodynamics of gauge fields}

Someone who claims to stand in the tradition of Wheeler and to be able to work out a geometrization of all known interactions is Eckehard Mielke with his Geometrodynamics of Gauge Fields (Mielke [1987]). ${ }^{30}$ Pretty much like Wheeler, Mielke is 'striving for a unified geometrical description of fundamental physical interactions' starting from general relativity which he thinks to be the 'prototype of a physical theory' (Mielke [1987], pp. 5 and 11). Moreover, Mielke shows a considerable historical and epistemological awareness of Weyl's theories of matter and explicitly claims to follow the tradition not only of Wheeler but also of Weyl's 1918 unified field theory (cf. Ibid., pp. 131-2; Mielke and Hehl [1988]). According to Mielke the problem with the latter two (though they were 'pursuing the right track') was that the geometrization programme was seen 'in a possibly too narrow frame' (Mielke [1987], p. 131).

According to Mielke, the appropriate mathematical tools for such a geometrization programme are the concepts of fibre bundles and differential forms. The appropriate structures to investigate then are the spaces of the 'internal' symmetry of the Yang-Mills gauge fields as additional dimensions of a higher dimensional, physical space-time manifold (cf. Ibid., p. 132). This means that interactions other than gravitation are accounted for by additional bundle spaces being attached to each point in space-time. Roughly speaking then, in the case of, say, the strong interaction between quarks, which is usually described by quantum chromodynamics, this would mean that a 'colour space' is attached to each point and that the interaction is described by 'geometrodynamic events' like parallel displacements (cf. Ibid., p. 13).

On this basis, Mielke claims that the 'description of fundamental interactions is [...] essentially building on geometrical concepts only' (Ibid., p. 131). In a sense this is surely true, but the question arises whether such a broad notion of geometry is what Wheeler (or Mie [1912] or Weyl [1918]) were aiming for. Of course, by using the language of fibre bundles for quantum chromodynamics one can describe the interaction between quarks as geometrodynamics in colour space. Apart from using concepts like 'parallel displacement', one can express important variables directly by means of the properties of a vector bundle. But, arguably, this is technical jargon rather than a genuine reduction of matter to space-time geometry in Wheeler's original sense. (Of course, a mathematician might argue that the

${ }^{30}$ I use Mielke as an example here although the mathematical inventory of his geometrization approach goes already back to, amongst others (Trautman [1973]; Wu and Yang [1975]; Drechsler and Mayer [1977]; Hehl and Šijački [1980]). See also (Trautman [1980]) for an overview. 
fibre bundle formalism has a certain connection to our geometrical intuition and that - within mathematics - it was derived from those intuitions; but this does not turn Mielke's approach into a Wheelerian geometrodynamics in any strong physical sense. ${ }^{31}$ )

Indeed even an analogy to Weyl's agent theory might be claimed; at least if one was willing to emphasize that in Mielke's approach the internal degrees of freedom of particles are not spatio-temporal but rather are a kind of 'transcendent attachment' to the four-dimensional world of appearances. So in this sense one might even claim that the transcendent reality Weyl was so vague about in 1926/27 may now be expressed in much more detail in terms of bundle spaces. Arguably, however, there is no concept of matter as being an agent. Parts of geometry have become transcendent, so to speak, but matter is still to be dissolved in that geometry. ${ }^{32}$

Another serious problem of an agent theoretic interpretation of Mielke's approach is given by its classical framework. The fibre bundle formalism itself is based on classical field theory, and so arguably this approach deviates strongly from Weyl's demand for a genuine role to be played by statistics in physics; and with it, as Weyl would presumably argue, it lacks the proper philosophical concepts of time and causation. Altogether then, the geometrodynamics of gauge fields turns out to have hybrid elements but on the whole shows a tendency towards the field theoretic, Cartesian approach to matter.

\subsection{Quantum gravity: quantum general relativity versus string theory}

Generally speaking, one central element of the physical approaches discussed in this section (apart perhaps from the Wheeler-Feynman approach) is the combination of general relativity and quantum physics. Somehow or other, Weyl, Wheeler, and Mielke all aim at a theory that brings together gravitation and quantum phenomena. But admittedly, most of the physicists today

31 Arguably, simply using some geometrically connotated expressions (or using a formalism originally derived from geometrical intuitions) does not mean that as a consequence physics is geometrodynamics; compare the following quote from (Weinberg [1972], p. 147), about the shift of geometrical concepts in physics from playing a genuine intuitive role to merely being some terminological hangover: 'It is therefore not surprising that Einstein and his successors have regarded the effects of a gravitational field as producing a change in the geometry of space and time. At one time it was even hoped that the rest of physics could be brought into a geometric formulation, but this hope was met with disappointment, and the geometric interpretation of the theory of gravitation has dwindled to a mere analogy, which lingers in our language in terms like "metric", "affine connection", and "curvature", but is not otherwise very useful.'

32 Though admittedly one could perhaps argue that there is a transcendental concept of matter involved here; namely insofar as the base manifold is not space-time itself (the gravitational interaction also takes place in a bundle space) but is merely an indexing device for points. 
consider their views to be rather exotic. So let me conclude this section with a discussion of what seem to be the two main routes towards a quantized theory of gravitation in contemporary physics. ${ }^{33}$

The first route is to start directly from general relativity and to apply heuristic quantization rules to gain 'quantum general relativity', as one might call it. Within quantum general relativity one can distinguish between covariant approaches which, for example, start from perturbative renormalization theory and view the transformation behaviour of gauge fields as being a geometrical aspect of the theory (in its quantized form famously leading to ghost fields). Both matter and field are then described by quantum fields (with different spin though) which are genuinely dynamical. So, in a sense, this genuine probabilistic approach can be understood as a kind of geometrodynamics in which geometry must not be stipulated separately but follows from the gauge principle. ${ }^{34}$ Apart from covariant there are also canonical approaches, the most prominent one presumably being loop quantum gravity in which no fixed background metric is assumed but space-time is conceived as a dynamic field which must be quantized directly. Other canonical approaches include metric formulations using the Wheeler-DeWitt equation. ${ }^{35}$

Following the second route one does not quantize general relativity directly or separately. Here, instead, one searches for a candidate for a unified quantum framework of all interactions. The most distinguished approach in this direction is string theory, assuming the basic constituents of physics to be one-dimensional objects (strings) instead of pointlike particles. In this case one investigates the general mechanics of such extended objects in hope of getting a framework for the whole of physics.

So quantum general relativity and string theory differ in their respective attitude towards physics: the former emphasizes and builds a theory on what seems to be a firm ground (namely, the structure of space-time and its description by general relativity), whereas the latter starts from a more general speculation about what matter might be and how it relates to (or even constitutes) space and time. Whereas quantum general relativity does not immediately (or necessarily) lead to an unified theory of all interactions, string theory is meant to be a theory of everything. Gravity is supposed to be

33 So in what follows I will say nothing about the different axiomatic and constructivist approaches in the quantum field theoretic descriptions of strong and electro-weak interactions; cf. (Dosch et al. [2005]) for this. For an overview of the two ways of quantizing gravity that I discuss here see (Kiefer [2006]).

34 See (Scharf [2001], pp. 115 and 204), who extends the causal approach in perturbative quantum field theory to the case of spin 2, where instead of a Lie algebra one gets the Einstein Lagrangian.

35 Since general relativity is sometimes called geometrodynamics, the metric formulation is sometimes called 'quantum geometrodynamics'; see, e.g. (Kiefer [2004], pp. 1 and 118), and (Kiefer [2006]). This, however, must not be confused with the special usage of this term in the context of a quantized version of Wheeler's geometrodynamic programme (cf. above). 
necessarily contained in string theory; here an effective low energy approximation gives the Einstein-Hilbert action of general relativity.

Generally speaking one might say that because of its different starting point string theory does not entertain such a prominent or even primordial concept of space-time as does quantum general relativity. ${ }^{36}$ In particular, the existence of extended objects in string theory has the important consequence that, unlike in canonical approaches to quantum general relativity, space-time cannot be assumed to be locally flat. The principle of background independence of general relativity cannot be implemented directly in string theory and an external background space-time is assumed (cf. Kiefer [2004], p. 279). ${ }^{37}$ So the two major ways of quantizing gravitation can be distinguished by the different status they attribute to general relativity and the claims, which follow from these, about what is firmly given or secured on the level of the description of four-dimensional space-time.

It has been argued that the concepts of quantum general relativity, as they are directly related to the classical theory of general relativity, are much better understood than those of string theory which are only related to concepts from quantum field theory which in turn are themselves poorly understood beyond the perturbative level (cf. Kiefer [2004], p. 3). This argument again relies on a particular emphasis and trustworthiness of general relativity as a kind of prototype description of four-dimensional space-time. (Indeed, one might argue for the exact opposite, namely that the fairly direct links between concepts in string theory and quantum field theory-like that of a particle or an S-matrix - are particularly welcome and that, e.g., loop quantum gravity lacks such links. ${ }^{38}$ However, I do not wish to discuss this here. My main point is simply that, according to its self-understanding, quantum general relativity has the advantage of an allegedly conceptually and historically firm origin in classical general relativity and heuristic quantization rules. ${ }^{39}$ )

${ }^{36}$ Putting it a little more formally, the difference in the formalism is that in string theory, unlike for instance, in loop quantum gravity, the space-time diffeomorphism group appears only as part of a much bigger structure; cf. (Isham [1994]) for an overview.

37 Details, however, are rather tricky and currently under discussion. Indeed the AdS/ CFT-correspondence (cf. below) in string theory comes close to background independence in some respect; see (Aharony et al. [2000]). Besides, Brunetti and Fredenhagen ([2006]) have done important work for showing that the covariant approach to quantum general relativity is background independent in the sense that the change of a given background is a symmetry of the theory. For a more general and philosophical discussion of background independence see also (Rovelli [2004]) and (Smolin [2006]).

38 Nicolai and Peeters ([2007]) are advocates of loop quantum gravity, but they concede that, in contrast to string theory, their approach 'must face up right away to the question of what an observable quantity is'.

39 See (Kiefer [2004], p. 21): 'The main advantage of [loop quantum gravity] is that the starting point is given. [...] The main disadvantage [of string theory] is that the starting point is entirely speculative.' Note that - although presumably unintended by the author - this phrasing fits with Weyl's distinction between Husserlian phenomenology (starting from a 'given') and Fichtean constructivism (starting from reflexive structures of the ego as being 'speculative' in the sense of 
So, like Weyl's unified field theory and like Wheeler's and Mielke's geometrodynamics, quantum general relativity is also primarily motivated by general relativity and starts from the allegedly firmly based concept of background independence. So in Weyl's sense, it might be described as tending towards a field theoretic understanding of matter. (I use the phrases 'might be' and 'tending' here since quantum general relativity does not aim at dissolving matter into pure extension and, given that it operates in the framework of quantum fields, does not dismiss all notions of probability or statistics. But although there are obviously hybrid elements in quantum general relativity, in particular as compared with string theory, the agent theoretic aspects seem to be rather small.)

In contrast, string theory starts from a more general speculation about what matter might be (other than just curved space-time or assumed pointlike particles) and that this matter is not necessarily, or from the beginning placed outright in ordinary four-dimensional space-time. The strings themselves are first described as being in a different (transcendent) sphere. In this respect string theory is rather similar to Weyl's agent theory and it is therefore not by chance that both entertain a 'holographic principle'. By this I mean a mathematical theorem which in the present context relates the so to speak primordial and constitutional sphere of matter with four-dimensional spacetime - or if one likes philosophical catchwords, it is something like a 'transcendental action principle'. Leibniz as the prime father of all agent theories of matter has already claimed that appearances in space and time are 'pictures' of a monadic transcendental reality (see, e.g., Leibniz [1996], p. 194). Indeed pretty much the same is true of Weyl's approach to matter of around 1925 and of string theory; namely that spatio-temporal events are-and now we can mathematically be a little more accurate than Leibniz - holograms of a transcendental reality. Holography here means that the physics of a (allegedly existing) region can be described by the fundamental degrees of freedom existing on the boundary of this region. In the case of Weyl's approach, the holographic principle was given by Gauss's theorem, which allowed Weyl to extract all physically relevant information from surface instead of volume integrals. In the context of string theory, the basic idea originated from the fact that the entropy of a black hole is proportional to the area of its horizon (Bekenstein-Hawking). Indeed, this is very similar to what Weyl did in his agent theory; as in the Bekenstein-Hawking case all relevant physical information of the gravitating system is located on the boundary of some spatial region which lacks a physically describable 'inside'. Moreover, in the current 
literature one even finds the Leibnizian claim that the four-dimensional world of appearance is a hologram. ${ }^{40}$

As I have just mentioned, the Bekenstein-Hawking entropy was mainly a heuristic tool. The actual holographic principle of string theory is the so-called AdS/CFT-correspondence. ${ }^{41}$ The physical relevance of this correspondence is indeed disputable and so in this respect one should, perhaps, speak of a 'conjecture'. However, insofar as it is a correct mathematical statement it is indeed analogous to Weyl's 1921 holographic principle. For Gauss's theorem itself is also a mathematical and not a physical statement.

So the fact that according to Weyl's agent theory matter is something transcendent and acts in space-time from beyond, is to some extent resembled by the way in which string theory starts with defining the action of a string on a two-dimensional world-sheet and then works its way to calculating the effects of the strings in four-dimensional space-time. This may suggest that in string theory the concept of time is something rather non-trivial; and indeed it is rather poorly understood. ${ }^{42}$ But in quantum general relativity things are also not straightforward, as it starts as a 'timeless' theory in the sense that it lacks an external time parameter. ${ }^{43}$ So it is difficult to relate these inner-physical concepts of time to Weyl's philosophical claims about time and causation. ${ }^{44}$ However, the preceding remarks might perhaps suffice to illustrate that some of the current concerns about the preconditions of spatio-temporal events are in some respect similar to Weyl's transcendental considerations about matter.

(Allow me two little comments on my last sentence: first, it was surely not meant to say that string theorists adopt or should adopt the whole natural philosophical framework of Weyl's agent theory. I even think that string theorists are indeed better off with avoiding, for instance, comparisons between matter and ego. Second, I also surely did not mean to advocate string theory

40 The idea goes back to ('t Hooft [1994]). Subsequently, (Susskind [1995]) explicitly claimed that, given that certain open questions could be answered, 'string theory provides us with a concrete example of a holographic world'.

${ }^{41}$ According to the AdS/CFT-correspondence string theory on space-times which asymptotically approach the product of an Anti-de-Sitter (AdS) and a compact space is completely described by a conformal field theory (CFT) of the boundary at infinity. The relation to Bekenstein-Hawking is then given by the fact that near the horizon of an extremal Reissner-Nordstrøm black hole space-time is $A d S_{2} \times S^{2}$.

${ }^{42}$ In perturbative string theory time appears as a 'coupling constant' in a two-dimensional quantum field theory; and non-perturbatively it must presumably be reconstructed from a holographic theory starting with an auxiliary space-time metric of the conformal field theory from which the physical space-time metric is to be derived. For details cf. (Horowitz [1995]).

${ }^{43}$ In the canonical approaches to quantum general relativity semiclassical time can be gained from expressions including integrals over space and functional derivatives of the three-metric. See (Kiefer [2004]) for details.

${ }^{44}$ Indeed, there have been completely different suggestions about how time could emerge in quantum gravity. In particular, as Majid ([2005]) has shown, a small amount of non-commutativity in the geometry of space could lead to a 'spontaneous time generation'; and indeed string theory and some canonical approaches in quantum general relativity (including loop quantum gravity) exhibit aspects of non-commutative geometry. 
over and above quantum general relativity. It is not the aim of this article to tell physicists what might or should be the most promising paths to follow. However, it is the aim of this article to make oppositions visible and to grasp them in a systematic historiography of theories of matter.)

\section{Wavering Between Freedom and Constraint}

In the previous section I have applied Weyl's distinction between substance, field, and agent theories of matter to recent physics and thereby continued the historiography of different understandings of matter which, according to Weyl, already started with the work of Descartes and Leibniz. So it is now time to reflect on the philosophical embedding and relevance for writing such a historiography of theories of matter.

Within the conceptual frame of Weyl's historiography a certain dialectic structure is apparent. Whereas substance theories are basically out of date (though they might pop up again from time to time in rather curious fashionsee the Wheeler-Feynman approach), there is a kind of wavering between the agent theory of matter as being the only genuinely dynamic view of matter, and pure field theory as the project of dissolving matter into geometry. Moreover, although the history of theories of matter is not strictly dichotomic in the sense that matter would always be assumed to be either a passive geometrical feature of space-time or an active transcendent (or even transcendental) agent, there still seems to be a point to (i) Weyl's distinction between the different general lines in the history of thought and (ii) Weyl's attempt to confine and reconcile those different lines by showing and discussing their historical seesaw. ${ }^{45}$ In 1924 , Weyl summarizes his meta-view on theories of matter as follows:

What is matter?-Today, after the destruction of substance views, the balance swings between dynamic [agent] and field theories of matter. An answer in a few words cannot be given and will never be given [...] Instead of assigning a short and final formula which one has in black and white and can carry home, this question like all fundamental questions assigns us with an infinite task (Weyl [1924], p. 510). ${ }^{46}$

45 One might even take Weyl's intertwined history and systematics as an explanatory foil for why today analytic philosophers of physics, when it comes to quantizing gravity, tend to focus their discussions on loop quantum gravity; see (Wüthrich [2006]) as an exemplary case and also for further references. Their main argument in favour of this approach is the background independence which they directly inherit from general relativity. Following Weyl, one might view this as a historical consequence of the fact that, generally speaking, analytic philosophers of physics grow up in a Humean rather than a Leibnizian tradition and normally do not tend to assume transcendent (let alone transcendental) material agents.

46 'Was ist Materie? - Nach der Vernichtung der Substanzvorstellung schwankt heute die Wage [sic!] zwischen der dynamischen und der Feldtheorie der Materie. Eine Antwort in wenigen Worten läßt sich nicht geben und wird sich niemals geben lassen [...] Statt vor eine kurze 
Obviously historical and systematic aspects go together here. There is a historical seesaw here between agent and field theories of matter. Given Weyl's explication of the respective philosophical background of agent and field theories, this seesaw can be understood as a wavering between 'freedom and constraint' (Freiheit und Gebundenheit). ${ }^{47}$ For according to Weyl agent theories of matter attempt to bring spontaneity into physics and to connect it with the genuine experience of causation of free human beings, whereas field physics with its 'complete rest in continuity' stays enclosed in the necessity of non-probabilistic 'pure law physics' (reine Gesetzesphysik).

This wavering between freedom and constraint also becomes apparent from what Weyl says, for instance, about the notion of continuity in mathematics (which, as already mentioned, is also intimately connected to what he thinks about physical continua). As with the case of matter, Weyl here presents the historical development of concepts as a seesaw process between views that take a mathematical continuum to be given once and for all (as, for instance, set theory does) and views according to which a continuum has to be actively and freely construed through decisions made by the mathematician (as, for instance, in the case of Brouwer's free choice sequences). Indeed for Weyl the wavering between freedom and constraint as a historical process can be found in all major areas of mathematics and physics - the reason for this being that according to Weyl human beings are fundamentally characterized by this wavering or tension. ${ }^{48}$ And consequently, it is exactly this wavering or tension that acts as the driving force of his whole book Philosophy of Mathematics and Natural Science (cf. Weyl [1927], especially pp. 53, 78 and 90).

Let me give another example to illustrate this point: in his 1925 paper 'On the current epistemological situation in mathematics' ('Die heutige Erkenntnislage der Mathematik'), Weyl writes about mathematics as standing at exactly this gulf between 'freedom and constraint' (Weyl [1925], p. 533). The article starts off with the remark that mathematics is the science of the infinite and then tells a long story about the to and fro between the concepts of passive being and active becoming in mathematics. Notably, however, the paper is called 'current epistemological situation in mathematics' and not 'a brief history of the infinite', or something similar. This is because history itself is part of the current situation, and especially then the prominent debate between intuitionism and formalism is viewed by Weyl as an historical

endgültige Formel, die man schwarz auf weiß nach Hause tragen kann, stellt uns diese Frage wie alle Fragen grundsätzlicher Art vor eine unendliche Aufgabe'.

${ }^{47}$ Cf. also (Weyl [1931a], pp. 3-4), and (Weyl [1934], p. 53), where he uses the English term 'restrictedness' instead of 'constraint'.

${ }^{48}$ Apart from the aforementioned passages see also (Weyl [1931a], p. 19), and (Weyl [1949]). 
instantiation of the overall wavering. So, as in the case of matter, history 'assigns us with an infinite task'.

This emphasis on a wavering between freedom and constraint as being related to the notions of infinity and finiteness, and also the way Weyl uses this to gain a systematic historiography shows his reception of German Idealism, in particular to the writings of Fichte. ${ }^{49}$ In the aforementioned paper, Weyl even makes this explicit. He says that it is only by looking at the historical wavering between freedom and constraint that one (re-)cognizes a 'rising third realm' and that it was the 'born-and-bred constructivist' Fichte who 'first entered this realm' (Weyl [1925], p. 540). (Of course, Weyl immediately adds that there are several things and in particular several 'a priori deductions' which Fichte was wrong about. According to Weyl, the details of the 'symbolic constructivism' he himself aims at have to come from other sources as well. As shown above, these sources include modern physics-especially relativity theory and quantum mechanics - and also some concepts from Leibniz. However, it is also clear that by eliciting matter from its state of being completely incommunicado and by writing a systematic history of science Weyl goes beyond Leibniz and beyond the scope of modern physics. And it is with respect to this general philosophical framework that Weyl is sympathetic towards Fichte and thinks that on the whole Fichte led constructivism on the right track.)

This particular intertwining of history and systematics, of explicating an ongoing historical development and to thereby gain some very general conceptual insights can be found in nearly all of Weyl's philosophical writings starting from about 1920. One can find it, for instance, also in the fourth edition of Space-Time-Matter from 1922 where Weyl opposes the view that the problem of space could have been solved 'at a glance' or 'with one flash' but necessarily needed a long history of works from people like Newton, Riemann, Einstein, and others (Weyl [1952], p. 148). This comment might help us to understand the difference between Weyl's view and that of Husserlian orthodoxy in 1922 (in which notions like that of a 'life world' did not exist yet). Weyl's particular phrasing here which makes use of an optical metaphor and so alludes to the original meaning of 'phenomenology' might indeed be understood as an early critique on a philosophical view that entertains the 'seeing of essences' (Wesensschau) as one of its core concepts. For on other occasions Weyl distinguishes Husserlian phenomenology from Fichtean constructivism by using exactly this notion of 'seeing' (das Sehen) as opposed to 'creative activity' (das Schöpferische) (Weyl [1925], p. 541). ${ }^{50}$

49 The difference from a Schelling-type approach here is discussed in (Sieroka [2007]).

50 This dichotomy is made even more explicit in (Weyl [1954b], p. 641), where he says that Fichte 'is anything but a phenomenologist, he is a constructivist of the purest sort' ('er ist alles andere als ein Phänomenologe, er ist ein Konstruktivist reinsten Wassers'). 
And, as he later makes it explicit: 'it is not enough to have one's eyes opened widely; [truth] must be gained by acting,; 51 and so Weyl claims that 'as for the opposition between constructivism and phenomenology, on the whole my sympathy is on his [Fichte's] side' (Weyl [1954b], p. 643). ${ }^{52}$

Going back to Weyl's distinction between theories of matter, it turns out that the metaphors Weyl is using to explicate phenomenology and pure field physics coincide to some extent; for both are opposed to 'activity', both are 'silent' in some respect, and rest in the supposedly given continuity of spatiotemporal appearances. Indeed, as already mentioned, phenomenology had been the major philosophical resource for Weyl's 1918 unified field theory. Similarly, the difference between the agent theory of matter and phenomenology is also evident from Weyl's strong notion of causation. ${ }^{53}$ Again and especially in relation to scientific experiments, Weyl emphasizes that a human being must understand itself as being the cause of certain happenings rather than being a silent observer (Weyl [1927], p. 147). This again is not so much a phenomenological point of view but rather follows Fichte-and indeed coincides to a large extent with Helmholtz's view on experiments in which the latter also followed Fichte (Heidelberger [1995], [1998]).

So much for the difference from phenomenology. But in how far does Weyl's thinking also differ from the other predominant view in German academia around 1920, namely neo-Kantianism? In particular, in how far does it differ from the Marburg School where Cassirer also wrote a systematic historiography of science and mathematics? ${ }^{54}$ To answer this question, let me start with Weyl's rather harsh critique on Kant himself. In Philosophie der Mathematik und Naturwissenschaften, he says that Kant's philosophical system suffers from being a doctrine of two separate worlds and that there is basically no possibility in Kant to get the four-dimensional world of

51 '[...] es genügt nicht, große Augen zu machen, [die Wahrheit] will durch Handeln gewonnen sein' (Weyl [1949], p. 334).

52 'In dem Gegensatz von Konstruktivismus und Phänomenologie liegt meine Sympathie im ganzen auf seiner Seite'.

53 Moreover, it is tempting to describe the relation between the Fichtean 'Wissenschaftslehre' and Husserlian phenomenology in terms of the following physical analogue: as in string theory (it being the most promising candidate for a modern variant of a Leibniz-Fichte agent theory of matter) where general relativity occurs inevitably as a low-energy effective theory, one might say that phenomenology (as compared with the 'Wissenschaftslehre') is the limit theory which assumes (rather than deduces) intuition. Anachronistically speaking, Fichte would surely not deny the Husserlian doctrine that the world around us appears as given (just as the string theorist does not deny general relativity). Fichte would also acknowledge the reasonableness of having a discipline which investigates the structure of what appears to us as given. However, Fichte would argue, there should also be a discipline which is concerned with how it comes that the world appears as given. The analogy to Weyl's theories of matter would then be the move from pure field physics describing the world of appearance to assuming matter to be an agent constitutive of those spatio-temporal appearances (fields).

54 See his Substanzbegriff und Funktionsbegriff and Philosophie der symbolischen Formen; i.e. (Cassirer [1994], [1988]). 
appearance into contact with the moral world of reason endowed creatures (Weyl [1927], p. 157). (Some years later in a letter Weyl even wrote that 'as I think the book shows, I do not take Kant very seriously. Wherever he comes to talk about problems (space, matter) which touch on science he falls far behind Leibniz'; additionally he characterizes himself as someone who 'is rather tempted to laugh about the details of Kant's thoughts than to furrow one's brow. ${ }^{55}$ )

As Weyl explicitly acknowledges in this context, it is Fritz Medicus whom he follows in his critique. ${ }^{56}$ Medicus was Weyl's colleague for philosophy at the ETH and the one who made Weyl read Fichte in the first place (See Sieroka [2007] for details). Medicus's critique ([1926], pp. 82-4) on Kant roughly goes like this: since space and time are forms of intuition and since the subject entertains causality as one of the categories of the understanding, the world of appearance is in this sense causally closed. But this concept of causality is obviously not Weyl's (or Medicus's) experiential notion of causation. According to Medicus, this closeness which is related in Kant to the notion of the thing-in-itself somehow separates the world of spatio-temporal appearances from what Kant says about the realm of freedom; i.e., of subjectivity and spontaneity. As Medicus puts it, 'all events taking place in space and time are a superfluous performance with respect to moral reality' (Ibid., p. 83). ${ }^{57}$ But this, Medicus and Weyl claim, is obviously wrong.

According to Medicus, the first philosopher who overcame the Kantian separation between the two worlds was Fichte. He did so by putting emphasis on the notion of life and human existence in the world. Fichte claimed that the central principle of all philosophy is that one can affect something (Ich wirke) (Fichte [1995], p. 2). He also maintained that true philosophy always has to start from life and that it must 'exhaust the human being as a whole' (Fichte [1971], p. 372, [1997], p. 202; cf., e.g. Medicus [1905], [1919], [1951], passim). He thereby initiated something like an anthropological turn in philosophy, after which the ingression and relevance of spontaneity and moral issues for our daily concerns was taken more seriously. According to Medicus, it was

55 Quoted from letters to Magdalene Aebi from 1948/49 (ETH-Bibliothek, Archive, Hs 91: 2-3: 'Übrigens glaube ich, zeigt das Buch [...], dass ich Kant nicht sonderlich ernst nehme. [...] Wo immer er auf Probleme zu sprechen kommt (Raum, Materie), die die Naturwissenschaft berühren, bleibt er weit hinter Leibniz zurück [...] Für jemanden, der wie ich über Kants Gedankengang im einzelnen eher zu lachen als die Stirn zu Denkerfalten zu legen geneigt ist [...].')

56 In (Weyl [1927], p. 157), he refers to (Medicus [1926]). In contrast (Mie [1948], p. 735), acknowledges a great indebtedness to Kant. This is interesting insofar as in the present context phenomenology, pure field physics and Kantianism might perhaps be thought of as being linked to one another and as standing in opposition to constructivism, agent theories, and Fichteanism.

57 'Das ganze in Raum und Zeit ablaufende Geschehen ist für die sittliche Wirklichkeit eine überflüssige Veranstaltung'. 
Fichte who, so to speak, got the agency of subjects into direct contact with spatio-temporal reality (cf. Medicus [1926], p. 84).

The fact that Fichte played such a crucial role for Medicus can partially be understood by Medicus's vita (Graf and Christophersen [2004]). His teachers included Windelband and Hensel and so (at least for some time) Medicus was under the influence of the Southwest German School of neo-Kantianism in which the works of Fichte played a prominent role-or at least had a much more prominent role than they did in the Marburg School (Heinz [1997]). However, since he also studied with Riehl and Eucken, other academic schools, including the then prominent Lebensphilosophie, also had a bearing on Medicus's philosophical development. So, what distinguishes Medicus's view in particular from that of the Marburg School, is his attitude towards Fichte and towards a rather strong notion of life. Moreover, it seems to be this critique that Weyl adopts from Medicus (supplemented perhaps by being annoyed by mathematical simple-mindedness, in particular that of Natorp) (cf. Weyl [1927], p. 99, [1925], p. 516). At least this is what Weyl later alludes to when he describes Cassirer's symbolic forms as being 'rather turbid filters for the light of truth' which fail to show or treat the 'unity of the luminous center' of the human being (Weyl [1954a], p. 630). Similar to Medicus, Weyl here opposes a purely functional definition of human beings which for him could never account for the concrete unity of being as actually experienced by the individual. ${ }^{58}$ (Besides, Weyl could apply basically the same critique against Husserlian phenomenology, which also lacked strong concepts of life or human existence. ${ }^{59}$ )

To sum up, Weyl's interpretation of Fichte is a constructivist one which at the same time puts emphasis on the concepts of life and experience. (Although it admittedly lacks resonance in English, the term 'transcendental pragmatism', Transzendentalpragmatismus, might come to mind here.) Such a reading of Fichte seems possible and in particular it seems to be a fruitful alternative to today's rather standard reading of Fichte as a philosophical foundationalist interested in some rather mystic self-relation of the ego. ${ }^{60}$ Moreover, I suggest that by explicating the historical seesaw of the concept of matter and of the mathematical accounts of the continuum Weyl showed the historical dimension of what Fichte called 'the wavering of the power of imagination'

58 During the 1920 s, this critique against Cassirer was first or at least most famously raised by Heidegger; cf. (Renz [2002], pp. 250-256 and 291).

59 See Weyl's manuscript on 'Man and the Foundations of Science' from 1949: 'Phenomenology had lunged out in all directions beyond the narrow boundaries of sensual data; but still its pure ego was like a spirit soaring above the waters, untainted by worldliness, and it was hard to conceive how it could ever surrender its immanence and become flesh, man among men.' (ETH-Bibliothek, Archive, Hs 91a: 28).

60 See, e.g. (Henrich [1993]). However, there are also Fichte scholars who read Fichte similarly to the way indicated here; cf., e.g. (Rockmore [1995]). 
(das Schweben der Einbildungskraft). According to Fichte, this wavering tempers the opposites between being bound and being free, between the finite and the infinite ego from which life and consciousness and then concepts of matter, space and time follow. ${ }^{61}$ By the same token, Weyl fulfils (at least in part) the Fichtean programme of philosophy as being the 'pragmatist historiography of the human mind' (Fichte [1997], p. 141, [1991], p. 69). Using Fichtean terminology one might therefore say that with his concept of a wavering between freedom and constraint and with his notions of life and of an arising third realm Weyl posits himself in between Husserlian phenomenology and Cassirer's philosophy of symbolic forms.

\title{
Acknowledgements
}

I am grateful to Deborah Bregenzer, Hugh Mellor, Peter Pesic, Tom Ryckman, Günter Scharf, Erhard Scholz, and Iulian Toader for their helpful comments on earlier drafts of this article. Parts of earlier versions were also presented at the Séminaire Riemann, Université Denis Diderot in Paris, at the EPSA07 conference in Madrid, and at the Seminar for Gravitation and Relativity Physics at the University of Cologne, and I would like to thank the audience members at all three locations for stimulating discussions.

\author{
ETH Zurich \\ Chair for Philosophy \\ RAC F 18 \\ 8092 Zurich \\ Switzerland \\ sieroka@phil.gess.ethz.ch
}

\section{References}

Aharony, O., Gubser, S. S., Maldacena, J., Ooguri, H. and Oz, Y. [2000]: 'Large $N$ Field Theories, String Theory, Gravity', Physics Reports, 323, pp. 183-386.

Bovet, E. [1922]: 'Die Physiker Einstein und Weyl antworten auf eine metaphysische Frage' ['The Physicists Einstein and Weyl Answer on a Metaphysical Question'], Wissen und Leben, 15, pp. 901-6.

Brunetti, R. and Fredenhagen, K. [2006]: 'Towards a Background Independent Formulation of Perturbative Quantum Gravity', in B. Fauser, J. Tolksdorf and E. Zeidler (eds), Quantum Gravity. Mathematical Models and Experimental Bounds, Basel: Birkhäuser, pp. 151-9.

${ }^{61}$ See, for instance, (Fichte [1979], pp. 29, 124 and 144-51), and (Fichte [1997], pp. 124 and 146). Fichte uses this metaphor of a 'wavering' to explicate his notion of 'intellectual intuition' in which both concepts and intuitions are closely intertwined. Again this marks a crucial difference to Kant who denies such a concept and for whom human insight or awareness always starts from intuition and then goes to concepts; see (Kant [1974], p. 604, B730). 
Cassirer, E. [1988]: Philosophie der symbolischen Formen [Philosophy of Symbolic Forms], Volume 1, (Die Sprache), Darmstadt: Wissenschaftliche Buchgesellschaft.

Cassirer, E. [1994]: Substanzbegriff und Funktionsbegriff [Substance and Function], Darmstadt: Wissenschaftliche Buchgesellschaft.

Descartes, R. [1992]: Die Prinzipien der Philosophie [Principles of Philosophy], Hamburg: Meiner.

Dosch, H. G., Müller, V. F. and Sieroka, N. [2005]: Quantum Field Theory in a Semiotic Perspective, Berlin: Springer.

Drechsler, W. and Mayer, M. E. [1977]: Fiber Bundle Techniques in Gauge Theories, Berlin: Springer.

Fichte, J. G. [1971]: Bericht über die Wissenschaftslehre und die bisherigen Schicksale derselben [Report on the Science of Knowledge and Its Fates Hitherto] (1806), Volume VIII of Fichtes Werke, Berlin: Walter de Gruyter \& Co.

Fichte, J. G. [1979]: Grundlage des Naturrechts nach Prinzipien der Wissenschaftslehre [Foundations of Natural Right According to the Principles of the Science of Knowledge], Hamburg: Meiner.

Fichte, J. G. [1991]: Über den Begriff der Wissenschaftslehre oder der sogenannten Philosophie [Concerning the Concept of the Science of Knowledge, or, of So-called Philosophy], Stuttgart: Reclam.

Fichte, J. G. [1995]: Das System der Sittenlehre nach den Prinzipien der Wissenschaftslehre [The System of Ethics According to the Principles of the Science of Knowledge], Hamburg: Meiner.

Fichte, J. G. [1997]: Grundlage der gesamten Wissenschaftslehre [Foundations of the Entire Science of Knowledge], Hamburg: Meiner.

Fogel, B. [2008]: Epistemology of a Theory of Everything: Weyl, Einstein, and the Unification of Physics, PhD Thesis, Graduate School, University of Notre Dame.

Friedman, M. [2005]: 'Transcendental Philosophy and Twentieth Century Physics', Philosophy Today, 49, pp. 23-9.

Graf, F. W. and Christophersen, A. [2004]: 'Neukantianismus, Fichte- und Schellingrenaissance: Paul Tillich und sein philosophischer Lehrer Fritz Medicus' ['NeoKantianism, Fichte- and Schelling-Renaissance: Paul Tillich and His Philosophical Teacher Fritz Medicus'], Zeitschrift für Neuere Theologiegeschichte [Journal for the History of Modern Theologie], 11, pp. 52-78.

Hehl, F. W. [1973]: 'Spin and Torsion in General Relativity. I. Foundations', General Relativity and Gravitation, 4, pp. 333-49.

Hehl, F. W. and Šijački, D. [1980]: 'Towards a Unified Gauge Theory of Gravitation and Strong Interactions?', General Relativity and Gravitation, 12, pp. 83-90.

Heidelberger, M. [1995]: 'Helmholtz als Philosoph' ['Helmholtz as Philosopher'], Deutsche Zeitschrift für Philosophie, 43, pp. 835-44.

Heidelberger, M. [1998]: 'Die Erweiterung der Wirklichkeit im Experiment' ['The Enlargement of Reality in Experiments'], in M. Heidelberger and F. Steinle (eds), Experimentalessays - Versuche zum Experiment [Experimental Essays Attempts Towards Experiment], Baden-Baden: Nomos, pp. 71-92. 
Heinz, M. [1997]: 'Die Fichte-Rezeption in der südwestdeutschen Schule des Neukantianismus' ['The Fichte-Reception in the Southwest German School of neo-Kantianism'], Fichte-Studien, 13, pp. 109-29.

Henrich, D. [1993]: 'Fichtes, "Ich"” ['Fichte's "I"”], in D. Henrich (ed.), Selbstverhältnisse [Self-Relations], Ditzingen: Reclam, pp. 57-82.

Hilbert, D. [1900]: 'Mathematische Probleme' ['Mathematical Problems'], Nachrichten der Königlichen Gesellschaft der Wissenschaften zu Göttingen, mathematischphysikalische Klasse, pp. 253-97.

Hilbert, D. [1915]: 'Die Grundlagen der Physik (Erste Mitteilung)' ['The Foundations of Physics (First Note)'], Nachrichten der Königlichen Gesellschaft der Wissenschaften zu Göttingen, mathematisch-physikalische Klasse, pp. 395-407.

Hochkirchen, T. [1999]: Die Axiomatisierung der Wahrscheinlichkeitsrechnung und ihre Kontexte [The Axiomatization of the Probability Calculus and its Contexts], Göttingen: Vandenhoeck \& Ruprecht.

Horowitz, G. T. [1995]: 'Spacetime in String Theory', New Journal of Physics, 7, 201.

Hume, D. [1975]: Enquiries Concerning Human Understanding and Concerning the Principles of Morals, Oxford: Clarendon Press.

Isham, C. J. [1994]: 'Prima Facie Questions in Quantum Gravity', in J. Ehlers and H. Friedrich (eds), Canonical Gravity: From Classical to Quantum, Berlin/ Heidelberg: Springer, pp. 1-21.

Kant, I. [1974]: Kritik der reinen Vernunft [Critique of Pure Reason] (Werkausgabe Band $I I I \& I V)$, Frankfurt (Main): Suhrkamp.

Kiefer, C. [2004]: Quantum Gravity, Oxford: Clarendon Press.

Kiefer, C. [2006]: 'Quantum Gravity-A Short Overview', in B. Fauser, J. Tolksdorf and E. Zeidler (eds), Quantum Gravity. Mathematical Models and Experimental Bounds, Basel: Birkhäuser, pp. 1-13.

Lachièze-Rey, M. and Luminet, J.-P. [1995]: 'Cosmic Topology', Physics Reports, 254, pp. 135-214.

Leibniz, G. W. [1982a]: Monadologie [Monadology], Hamburg: Meiner.

Leibniz, G. W. [1982b]: Specimen Dynamicum [Dynamics], Hamburg: Meiner.

Leibniz, G. W. [1996]: Neue Abhandlungen über den menschlichen Verstand [New Essays on Human Understanding], Hamburg: Meiner.

Majid, S. [2005]: 'Noncommutative Model with Spontaneous Time Generation and Planckian Bound', Journal of Mathematical Physics, 46, p. 103520.

Mancosu, P. and Ryckman, T. A. [2005]: 'Geometry, Physics and Phenomenology: Four Letters of O. Becker to H. Weyl', in V. Peckhaus (ed.), Oskar Becker und die Philosophie der Mathematik [Oskar Becker and the Philosophy of Mathematics], München: Wilhelm Fink, pp. 153-227.

Medicus, F. [1905]: J. G. Fichte. Dreizehn Vorlesungen gehalten an der Universität Halle [J. G. Fichte. Thirteen Lectures Delivered at the University of Halle], Berlin: Reuther \& Reichard.

Medicus, F. [1919]: 'Die religiöse Mystik und die klassische deutsche Philosophie' ['Religious Mysticism and Classical German Philosophy'], Beiträge zur Philosophie des deutschen Idealismus, 1, pp. 158-69. 
Medicus, F. [1926]: Die Freiheit des Willens und ihre Grenzen [The Freedom of Will and Its Limits], Tübingen: J.C.B. Mohr (Paul Siebeck).

Medicus, F. [1951]: Menschlichkeit. Die Wahrheit als Erlebnis und Verwirklichung [On Being Human: The Life of Truth and Its Realization], Zürich: Artemis-Verlag.

Mie, G. [1912a]: 'Grundlagen einer Theorie der Materie: Erste Mitteilung' ['Foundations of a Theory of Matter: First Communication'], Annalen der Physik, 37, pp. 511-34.

Mie, G. [1912b]: 'Grundlagen einer Theorie der Materie: Zweite Mitteilung' ['Foundations of a Theory of Matter: Second Communication'], Annalen der Physik, 39, pp. 1-40.

Mie, G. [1925]: Das Problem der Materie [The Problem of Matter], Freiburg: Speyer \& Kaerner.

Mie, G. [1948]: 'Aus meinem Leben' ['About My Life'], Zeitwende, 19, pp. 733-43.

Mielke, E. W. [1987]: Geometrodynamics of Gauge Fields: On the Geometry of Yang-Mills and Gravitational Gauge Theories, Berlin: Akademie.

Mielke, E. W. and Hehl, F. W. [1988]: 'Die Entwicklung der Eichtheorien: Marginalien zu deren Wissenschaftsgeschichte' ['The Development of Gauge Theories: Side Notes on the History of Science'], in W. Deppert, K. Hübner, A. Oberschelp and V. Weidemann (eds), Exact Sciences and their Philosophical Foundations: Vorträge des Internationalen Hermann-Weyl-Kongresses, Kiel 1985, Frankfurt (Main): Peter Lang, pp. 191-232.

Misner, C. W. and Wheeler, J. A. [1957]: 'Classical Physics as Geometry: Gravitation, Electromagnetism, Unquantized Charge, and Mass as Properties of Curved Empty Space', Annals of Physics, 2, pp. 525-603.

Nicolai, H. and Peeters, K. [2007]: 'Loop and Spin Foam Quantum Gravity: A Brief Guide for Beginners', in E. Seiler and I.-O. Stamatescu (eds), Approaches to Fundamental Physics: An Assessment of Current Theoretical Ideas, Berlin: Springer, pp. 151-84.

Pauli, W. [1920]: 'Relativitätstheorie' ['Theory of Relativity'], in A. Sommerfeld (ed.), Enzyklopädie der mathematischen Wissenschaften [Encyclopedia of the Mathematical Sciences], Volume V, Part 2, Leipzig: Teubner, pp. 539-775.

Poincaré, H. [1906]: 'Sur la dynamique de l'électron', Rendiconti del Circolo matematico di Palermo, 21, pp. 129-76.

Renz, U. [2002]: Die Rationalität der Kultur: Zur Kulturphilosophie und ihrer transzendentalen Begründung bei Cohen, Natorp und Cassirer [The Rationality of Culture: On the Philosophy of Culture and Its Transcendental Foundation in Cohen, Natorp, and Cassirer], Volume 8 of Cassirer Forschungen, Hamburg: Meiner.

Rockmore, T. [1995]: 'Fichtean Circularity, Antifoundationalism, and Groundless System', Idealistic Studies, 25, pp. 107-24.

Rovelli, C. [2004]: Quantum Gravity, Cambridge: Cambridge University Press.

Ryckman, T. A. [2005]: The Reign of Relativity: Philosophy in Physics 1915-1925, Oxford: Oxford University Press.

Schäfer, D. [1967]: Die Rolle der Einbildungskraft in Fichtes Wissenschaftslehre von 1794/95 [The Role of the Imagination in Fichte's Science of Knowledge of 1794/95]; Dissertation, Philosophy Department, University of Köln. 
Scharf, G. [2001]: Quantum Gange Theories: A True Ghost Story, New York: John Wiley \& Sons.

Schelling, F. W. J. [1985]: 'Einleitung zu dem Entwurf eines Systems der Naturphilosophie' ['Introduction to the Sketch of a System of the Philosophy of Nature'], in Ausgewählte Schriften 1, Frankfurt (Main): Suhrkamp, pp. 337-94.

Schelling, F. W. J. [2000]: System des transzendentalen Idealismus [System of Transcendental Idealism], Hamburg: Meiner.

Scholz, E. [1995]: 'Hermann Weyl's 'Purely Infinitesimal Geometry', in S. D. Chatterji (ed.), in Proceedings of the International Congress of Mathematicians, Zürich, Switzerland 1994, Basel: Birkhäuser, pp. 1592-1603.

Scholz, E. [2007]: 'The Changing Concept of Matter in H. Weyl's Thought, 19181930', in V. F. Hendricks, K. F. Jørgensen, J. Lützen and S. A. Pedersen (eds), Interactions: Mathematics, Physics and Philosophy, 1860-1930, Dordrecht: Springer, pp. 281-305.

Sieroka, N. [2007]: 'Weyl's 'Agens Theory' of Matter and the Zurich Fichte' ['Surroundings. Symbolic Constructivism Following Hermann Weyl and Fritz Medicus'], Studies in History and Philosophy of Science, 38, pp. 84-107.

Sigurdsson, S. [1991]: Hermann Weyl, Mathematics and Physics, 1900-1927, PhD Thesis, Department of the History of Science, Harvard University.

Smolin, L. [2006]: 'The Case for Background Independence', in D. Rickles, S. French and J. Saatsi (eds), The Structural Foundations of Quantum Gravity, Oxford: Oxford University Press, pp. 196-239.

Susskind, L. [1995]: 'The World as a Hologram', Journal of Mathematical Physics, 36, pp. 6377-96.

't Hooft, G. [1994]: 'Dimensional Reduction in Quantum Gravity', in A. Ali, J. Ellis and S. Randjbar-Daemi (eds), Salamfestschrift, Volume 4 of World Scientific Series in 20th Century Physics, Singapore: World Scientific, pp. 284-96.

Tietjen, H. [1980]: Fichte und Husserl: Letztbegründung, Subjektivität und praktische Vernunft im transzendentalen Idealismus [Fichte and Husserl: Ultimate Foundation, Subjectivity, and Practical Reason in Transcendental Idealism], Frankfurt (Main): Vittorio Klostermann.

Trautman, A. [1973]: 'Theory of Gravitation', in J. Mehra (ed.), The Physicist's Conception of Nature, Dordrecht: Reidel Publishing, pp. 179-98.

Trautman, A. [1980]: 'Fiber Bundles, Gauge Fields, and Gravitation', in A. Held (ed.), General Relativity and Gravitation, Volume 1, New York/London: Plenum Press, pp. 287-308.

Vizgin, V. P. [1994]: Unified Field Theories in the First Third of the 20th Century, Basel: Birkhäuser.

von Mises, R. [1919]: 'Grundlagen der Wahrscheinlichkeitsrechnung' ['Foundations of the Probability Calculus'], Mathematische Zeitschrift, 5, pp. 52-99.

von Mises, R. [1928]: Wahrscheinlichkeit, Statistik und Wahrheit [Probability, Statistics, and Truth], Wien: Julius Springer.

Weinberg, S. [1972]: Gravitation and Cosmology: Principles and Applications of the General Theory of Relativity, New York: John Wiley \& Sons. 
Weyl, H. [1918]: 'Gravitation und Elektrizität' ['Gravitation and Electricity'], Sitzungsberichte der Königlich Preußischen Akademie der Wissenschaften zu Berlin [Collected Papers, Volume I-IV], pp. 465-80. Quoted from the reprint in Chandrasekharan, K. (ed) [1968]: Weyl's Gesammelte Abhandlungen (GA), Volume I-IV, Berlin: Springer, GA 31: II, pp. 29-42.

Weyl, H. [1919]: 'Eine neue Erweiterung der Relativitätstheorie' ['A New Enhancement of the Theory of Relativity'], Annalen der Physik, 59, pp. 101-33; (GA 34: II, pp. 55-87).

Weyl, H. [1920]: 'Das Verhältnis der kausalen zur statistischen Betrachtungsweise in der Physik' ['The Relation Between Causal and Statistical Approaches in Physics'], Schweizerische Medizinische Wochenzeitschrift, 50, pp. 737-41; (GA 38: II, pp. 113-22).

Weyl, H. [1921]: 'Feld und Materie' ['Field and Matter'], Annalen der Physik, 65, pp. 541-63; (GA 47: II, pp. 237-59).

Weyl, H. [1923]: Raum - Zeit - Materie [Space - Time - Matter], 5th edition, Berlin: Springer.

Weyl, H. [1924]: 'Was ist Materie?' ['What Is Matter?'], Die Naturwissenschaften, 12, pp. 561-8; 585-93, 604-11. (GA 66: II, pp. 486-510).

Weyl, H. [1925]: 'Die heutige Erkenntnislage in der Mathematik' ['On the Current Epistemological Situation in Mathematics'], Symposion, 1, pp. 1-23; (GA 67: II, pp. 511-42).

Weyl, H. [1927]: Philosophie der Mathematik und Naturwissenschaft [Philosophy of Mathematics and Natural Science], München: Oldenbourg Verlag.

Weyl, H. [1928]: 'Diskussionsbemerkungen zu dem zweiten Hilbertschen Vortrag über die Grundlagen der Mathematik' ['Comments on Hilbert's Second Lecture on the Foundations of Mathematics'], Abhandlungen aus dem mathematischen Seminar der Hamburgischen Universität, 6, pp. 86-8; (GA 77: III, pp. 147-9).

Weyl, H. [1929]: 'Gravitation and the Electron', The Rice Institute Pamphlet, 16, pp. 280-95; (GA 84: III, pp. 229-44).

Weyl, H. [1931a]: Die Stufen des Unendlichen [The Stages of the Infinite], Jena: Gustav Fischer.

Weyl, H. [1931b]: 'Geometrie und Physik' ['Geometry and Physics'], Die Naturwissenschaften, 19, pp. 49-58; (GA 93: III, pp. 336-45).

Weyl, H. [1932]: The Open World, New Haven: Yale University Press.

Weyl, H. [1934]: Mind and Nature, Philadelphia: University of Pennsylvania Press.

Weyl, H. [1949]: 'Wissenschaft als symbolische Konstruktion des Menschen' ['Knowledge as a Symbolic Construction of Human Beings'], Eranos-Jahrbuch, 1948, pp. 375-431; (GA 142: IV, pp. 289-345).

Weyl, H. [1952]: Space - Time - Matter; Mineola (N.Y.): Dover Publications. (English translation of the 4th edition of Raum - Zeit - Materie).

Weyl, H. [1954a]: 'Address on the Unity of Knowledge delivered at the Bicentennial Conference of Columbia University', Columbia University in the City of New York Bicentennial Celebration. (GA 165: IV, pp. 623-30). 
Weyl, H. [1954b]: 'Erkenntnis und Besinnung (Ein Lebensrückblick)' ['Insight and Reflection'], Studia Philosophica, Jahrbuch der Schweizerischen Philosophischen Gesellschaft Annuaire de la Société Suisse de Philosophie. (GA 166: IV, pp. 631-49).

Weyl, H. [1988]: Riemanns geometrische Ideen, ihre Auswirkung und ihre Verknüpfung mit der Gruppentheorie [Riemann's Geometric Ideas, Their Impact, and Their Relationships to Group Theory], Berlin: Springer.

Weyl, H. [2000]: Philosophie der Mathematik und Naturwissenschaft [Philosophy of Mathematics and Natural Science], München: Oldenbourg Verlag. (Retranslation of the revised and enlarged American edition from 1949).

Wheeler, J. A. [1961]: 'Geometrodynamics and the Problem of Motion', Reviews of Modern Physics, 33, pp. 63-78.

Wheeler, J. A. [1968]: Einsteins Vision: Wie steht es heute mit Einsteins Vision, alles als Geometrie aufzufassen? [Einstein's Vision: What Is the Current Status of Einstein's Vision to Conceive of Everything as Geometry?], Berlin: Springer.

Wheeler, J. A. [1986]: 'Hermann Weyl and the Unity of Knowledge', American Scientist, 74, pp. 366-75.

Wheeler, J. A. and Feynman, R. P. [1949]: 'Classical Electrodynamics in Terms of Direct Interparticle Action', Reviews of Modern Physics, 21, pp. 425-33.

Wu, T. T. and Yang, C. N. [1975]: 'Some Remarks about Unquantized Non-Abelian Gauge Fields', Physical Review D, 12, pp. 3843-4.

Wüthrich, C. [2006]: Approaching the Planck Scale From a Generally Relativistic Point of View: A Philosophical Appraisal of Loop Quantum Gravity, PhD Thesis, Faculty of Arts and Sciences, University of Pittsburgh. 